\title{
A community-based feasibility randomized controlled study to test food-specific inhibitory control training in people with disinhibited eating during COVID-19 in Italy
}

\section{Valentina Cardi ( $\nabla$ valentina.cardi@unipd.it)}

University of Padova: Universita degli Studi di Padova https://orcid.org/0000-0002-7763-7099

\section{Valentina Meregalli}

University of Padova: Universita degli Studi di Padova

\section{Elisa Di Rosa}

University of Padova: Universita degli Studi di Padova

Rossella Derrigo

University of Padova: Universita degli Studi di Padova

Chiara Faustini

University of Padova: Universita degli Studi di Padova

Johanna Louise Keeler

King's College London

\section{Angela Favaro}

University of Padova: Universita degli Studi di Padova

Janet Treasure

King's College London

Natalia Lawrence

University of Exeter

\section{Research Article}

Keywords: App, Binge eating, Bulimia nervosa, Depression, Food addiction.

Posted Date: February 10th, 2022

DOI: https://doi.org/10.21203/rs.3.rs-1328258/v1

License: (c) (i) This work is licensed under a Creative Commons Attribution 4.0 International License.

Read Full License 


\section{Abstract}

\section{Purpose}

The aim of this study was to expand the evidence on the feasibility and impact of food-specific inhibitory control training in a community sample of people with disinhibited eating.

\section{Methods}

Recruitment and data collection were conducted during the COVID-19 outbreak, in Italy. Ninety-four adult individuals with disinhibited eating were randomised to one of two conditions: App-based food-specific inhibitory control training or waiting list. Participants were assessed at baseline, end of intervention (two weeks following baseline) and follow-up (one week later). The assessment measures included questionnaires about eating behaviour and mood.

\section{Results}

Seventy-three percent of the sample reported a diagnosis of binge eating disorder, and $20.4 \%$ a diagnosis of bulimia nervosa. Retention rates were $77 \%$ and $86 \%$ for the food-specific inhibitory control training and the waiting list conditions, respectively. Almost half of the participants allocated to the training condition completed the "recommended" dose of training (i.e., 10 or more sessions). Those in the training condition reported lower levels of wanting for high-energy dense foods $(p<0.05)$, a trend for lower levels of perceived hunger $(p=0.07)$, and lower levels of depression $(p<0.05)$. Binge eating symptoms, disinhibition, wanting for high-energy dense foods, stress and anxiety were significantly lower at end of intervention, compared to baseline $(\mathrm{p}<.05)$.

\section{Conclusion}

Findings corroborate the feasibility of food-specific inhibitory control training, and its impact on highenergy dense foods liking. The study expands the evidence base for food-specific inhibitory control training by highlighting its impact on perceived hunger and depression. The mechanisms underlying these effects remain to be clarified.

Level of Evidence: Level I, Evidence obtained from at least one properly designed randomized controlled trials; systematic reviews and meta-analyses; experimental studies.

\section{Introduction}

Eating disorders (ED) are mental illnesses characterized by high mortality rates and disability [1]. Evidence-based, recommended psychological interventions, such as cognitive behavioural therapy or family-based therapy can be effective for some, although treatment follow-up rates remain disappointing (e.g. less than 50\%)[2-4], remission rates at one year can be $20 \%$ or lower [2], and one in five might develop a chronic form of the disorder [5]. A recent study assessed patients with anorexia nervosa or 
bulimia nervosa at 22-year follow-up and found that approximately a third had not recovered over time [6].

The COVID-19 pandemic has posed additional challenges to the treatment of eating disorders, due to a worldwide increase in the incidence of eating disorders behaviours in the community and a deterioration of symptoms in patients [7]. An area of particular relevance is the negative impact that the pandemic and social distancing have had on the use of unhealthy habits, such as the over overconsumption of unhealthy foods. Studies in the Italian population for example, have demonstrated a tendency to gain weight during lockdown [8] and also increased rates of emotional eating and binge eating $[9,10]$.

Emotional eating is defined as overeating in response to unpleasant emotional states (e.g. anger, sadness, guilt) [11], whereas binge eating is defined as the consumption of an objectively large amount of food in a discrete period of time, while perceiving loss of control and intense distress [12]. Both emotional eating and binge eating are characterised by disinhibited eating and underlined by specific emotional and cognitive processes. Increased negative affect and weakened inhibitory control are the most commonly identified mechanisms when exploring the maintenance of disinhibited eating in adolescent $[13,14]$ and adult populations [15-17]. These processes are not completely independent, in that negative emotions might impair people's abilities to inhibit prepotent responses $[18,19]$. There is initial evidence that deficits in emotion regulation and inhibitory control might be more accentuated in individuals with a greater proneness to show addictive-like responses to highly processed foods [20]. This behavioural phenotype has been described in the literature as "food addiction", e.g. [21], and is characterised by cravings for highly processed foods [22] and a greater tendency to use these foods to cope with negative emotions [23]. These findings indicate that interventions aimed at improving inhibitory control and reducing negative affect might be helpful in targeting disinhibited eating and that they might be particularly helpful among those with the food addiction phenotype.

Computerised and App-based trainings have been developed in recent years to improve general, and foodspecific inhibitory control. These trainings adopt a modified version of the stop-signal task or of the go/no-go paradigms, in which high-calorie foods are repeatedly associated with response suppression and motor inhibition. In non-clinical populations, food-specific inhibitory control trainings have proven effective in reducing unhealthy eating, with interventions employing go/no-go paradigms producing the strongest effects $[24,25]$. In a recent study, the use of an App-based inhibitory control training offered in addition to treatment as usual was associated with reductions in eating disorder psychopathology (standardised between-group effect sizes (SES) $=-0.57,95 \% \mathrm{Cl}[-1.12,-0.03]$ ) and high energy-dense food valuation (SES $=-0.61,95 \% \mathrm{Cl}[-0.87,-0.05]$ ) in people with bulimia nervosa or binge eating disorder, compared to treatment as usual alone [26]. These findings mirror previous evidence demonstrating the association between the use of a computerised based food-specific inhibitory control training and moderate-to-large reductions in binge eating frequency ( $d s=0.35,95 \% \mathrm{Cl}-0.16$ to 0.85 ), eating disorder psychopathology ( $\mathrm{ds}=0.22,95 \% \mathrm{Cl}-0.29$ to 0.72 ), and high energy dense food valuation compared to general inhibitory control training (ds $0.36,95 \% \mathrm{Cl}-0.18,0.90$ ) in patients with binge eating symptoms [27]. 
The present study was aimed at replicating and expanding these findings. The feasibility and efficacy of the App-based food-specific inhibitory training used by Keeler et al. [26] were tested during lockdown in Italy, in adults reporting overeating. Based on previous findings, the hypothesis was that food-specific inhibitory training would be associated with a greater reduction in binge eating episodes, compared to a waiting list. Between-group differences in changes in binge eating-related processes (i.e., high energydense food liking and wanting, cognitive restraint, disinhibition and hunger), and depression, anxiety and stress were also evaluated. Finally, the impact of food addiction on changes in binge eating frequency and eating- related processes was assessed.

\section{Methods}

\section{Participants}

Participants were recruited through flyers and informative materials published on social media, and through referrals from private nutritionists, non-profit organizations, and eating disorder clinical services. Inclusion criteria were assessed through a self-reported screening form and included the following: 18 years old or older, fluent in Italian, owning a mobile device, and reporting episodes of binge-eating (defined as eating an objectively large amount of food in a discrete period of time, while experiencing a sense of lack of control and intense associated distress) or overeating (defined as episodes of eating more than is necessary to sustain oneself or that is physically comfortable [28]) over the previous three months. Exclusion criteria were a diagnosis of Anorexia Nervosa, a Body Mass Index (BMI) lower than 18.5 , and the presence of a visual impairment that could not be corrected.

\section{Sample size estimation}

Scholars recommend sample sizes between 24 and 50 participants for feasibility studies [29, 30]. Previous studies using the same application and version of the training found differences in food valuation of high-energy dense foods in a sample of 40 individuals. In this study, the goal was to recruit a minimum of 40 participants/group.

\section{Design and Randomisation}

One-hundred and ten participants were screened for eligibility and 94 individuals were included in the study. A random number generator (https://randomizer.org) was used to assign participants to the intervention (FoodT training; $\mathrm{N}=44$ ) or the control (Waiting list, $\mathrm{N}=50$ ) condition. The Consort Diagram (figure 1) describes the flow of participation in the study.

\section{Food-Specific go/no-go Training (FoodT)}

The food-specific go/no-go training was delivered through the FoodT app, a mobile application developed at the University of Exeter [31]. Participants were invited to complete at least 10 training sessions during a period of two weeks. Each training session consisted of three blocks, and it lasted about five minutes.

During each block, 32 images were individually presented on the screen for $1500 \mathrm{~ms}$, with an interstimulus 
interval of $500 \mathrm{~ms}$. Presented images included eight low energy-dense foods (e.g. fruits, vegetables, and rice cakes), eight high energy-dense foods (e.g. chocolate, cake, crisps), and 16 neutral objects (e.g. stationery, clothing). One hundred ms after picture presentation, a red or green circle appeared around the image. Participants were required to tap the image on the screen when the object was circled in green ("go" trials) and to inhibit the response when the object was circled in red ("no-go" trials). Low- energy and high-energy dense food pictures were always paired with "go" and "no-go" cues respectively, while neutral objects were paired with either "go" or "no-go" cues (each $50 \%$ of times). Participants received feedback on their mean accuracy and reaction time at the end of each block. We analysed training task performance data to check that participants were accurately engaged in the training and showed evidence of learning the target stimulus-response associations (a 'manipulation check'). Participants could choose up to three categories of high-energy-dense foods to include in the training. Figure 2 provides examples of "go" and "no-go" stimuli.

\section{Assessment}

\section{Demographic variables}

At baseline, participants completed a demographic questionnaire, which included questions on age, gender, weight, height, nationality, years of education, profession, current/previous mental health or medical problems and use of psychiatric medications.

\section{Measures of eating behaviour and mood}

At baseline and end of intervention participants completed the following scales: (1) the Binge Eating Scale [32], a 16-item scale for the assessment of binge eating behaviour (Cronbach's alpha in this study=0.88), (2) the Three Factors Eating Questionnaire (TFEQ) [33], a 51-item scale for the assessment of three dimensions of eating behaviour: Cognitive Restraint (Cronbach's alpha in this study=0.87), Disinhibition (Cronbach's alpha in this study=0.69), and Hunger (Cronbach's alpha in this study=0.75), (3) the Yale Food Addiction Scale (YFAS) [21], a 25-item scale for the assessment of food addiction (Cronbach's alpha in this study=0.97), and (4) the Depression Anxiety Stress Scales - Short Version (DASS-21) [34], a 21-item scale for the assessment of Depression (Cronbach's alpha in this study=0.84), Anxiety (Cronbach's alpha in this study=0.71), and Stress (Cronbach's alpha in this study $=0.85$ ). Moreover, participants' levels of "liking" and "wanting" of 30 low- and high-energy dense foods were assessed using a visual analogue scale ranging from 0 to 10 . The food items were different from those used in the training but belonged to the same categories (see https://osf.io/c8z6x/for the images, taken from [35]). All the measures, except for the TFEQ were collected also at follow-up.

\section{Procedure}

After providing written consent, participants completed the baseline questionnaires via the online platform Qualtrics. Subsequently, they were randomly assigned to the food-specific training condition or to the waiting list condition. Participants assigned to the training condition received an email with instructions to download and use the FoodT application and were encouraged to complete at least 10 
training sessions in the following two weeks. The contents of the App were in English, but participants were provided with an explanatory video to describe and demonstrate its usage. At the end of the twoweek period (end of intervention), and one week later (follow-up), they completed the same questionnaires completed at baseline, with the exception of the demographic questionnaire. Participants assigned to the waiting-list condition received instructions on how to use the FoodT application following completion of the follow-up assessment.

\section{Statistical Analyses}

Generalised linear mixed models were calculated using the Ime4 package [36] in R 3.6.1. A model was calculated for each of the following dependent variables: total score of the BES; Cognitive Restraint subscale, Hunger subscale, and Disinhibition subscale of the TFEQ; Anxiety, Stress and Depression subscales of the DASS-21; and food liking and wanting for high-dense energy foods. The factors Group, Time (baseline, end of intervention, follow-up) and the interaction between Group and Time were included as fixed factors in the models. The categorial variable related to the possible presence of food addiction (Food Addiction) was included in the models calculated for the BES, TFEQ subscales, food liking and wanting. Participants' identity was included as a random factor to control for repeated measurements of the same subject in all models performed.

The significance of the full model was established by comparing this model with the model that included only the random factor (null model) using the likelihood ratio test. The model fit and the over-dispersion were checked using the DHARMa 0.3.3.0 package [37]. The significance value of each factor was derived using the "drop1" function [38]. The multcomp package [39] was used to derive significance values for Group by Time interactions (Ismeans function) and for the post-hoc comparisons conducted on the Time variable ( $g / h t$ function). The Tukey post-hoc correction was applied.

\section{Results}

\section{Participants' characteristics}

Participants' demographic and clinical characteristics are described in Table 1. There were no significant between-group differences in baseline characteristics (all $p>0.05$ ). With the exception of four individuals, all participants identified themselves with the female gender (95.7\%). Almost half (54.2\%) were aged 3554 years. Participants had completed on average 14 years of education. The mean body mass index (BMI) was 28.82 ( $S D=7.67)$, at the upper end of the overweight category. Seventy-three percent of the sample reported a diagnosis of binge eating disorder and $20.4 \%$ a diagnosis of bulimia nervosa. Almost $40 \%$ of the sample $(38.4 \%)$ were receiving psychological therapy at the time of participation; $29.1 \%$ were attending nutritional counselling and only a very small minority (5.8\%) was taking psychiatric medication. Almost half of the sample reported suffering from comorbid depressive symptoms (41.5\%) and anxiety (45.7\%). 
On average, participants reported moderate levels of binge eating symptoms [40], and high levels of attempts to restrain eating, disinhibition, and hunger on the TFEQ scale [41]. Just over half of the sample reported a possible diagnosis of food addiction based on the answers to the Yale Food Addiction Scale (i.e., three or more symptoms in addition to clinically significant impairment or distress) [21]. Participants reported moderate levels of anxiety, severe levels of depression and extremely severe levels of stress on the DASS-21 [42].

The group allocated to the FoodT condition completed on average 11 training sessions ( $\min =1, \max =30$ ) over the two-week intervention period. Twenty-five participants completed 10 or more sessions (56.8\% of the sample). Forty participants completed a minimum of four sessions (two sessions/week, $90.9 \%$ of the sample). Training was completed to high levels of accuracy (Mean $=99.2 \%, S D=0.66$ ) and participants showed the expected learning of go/no-go contingencies during training. Paired-sample t-tests indicated significantly faster reaction times for low-energy dense foods (Mean=717.37, SD=81.13) compared to filler items (Mean=732.15, $\mathrm{SD}=82.15 ; \mathrm{t}(33)=-4.51, \mathrm{p}<.0001)$, consistent with learning to "go" to low-energy dense foods. Participants also made fewer no-go errors to high-energy dense foods (Mean $=0.18 \%$, $S D=0.4$ ) compared to filler items (Mean $=0.5 \%, S D=0.7 ; t(33)=2.46, p=.02$ ), suggesting they had learned to withdraw a motor response to unhealthy foods. 
Table 1

Participants' demographic and clinical characteristics. These are described as frequencies (n) or mean (M) and standard deviation (SD). TFEQ = Three Factors Eating Questionnaire. DASS= Depression Anxiety and Stress Scales.

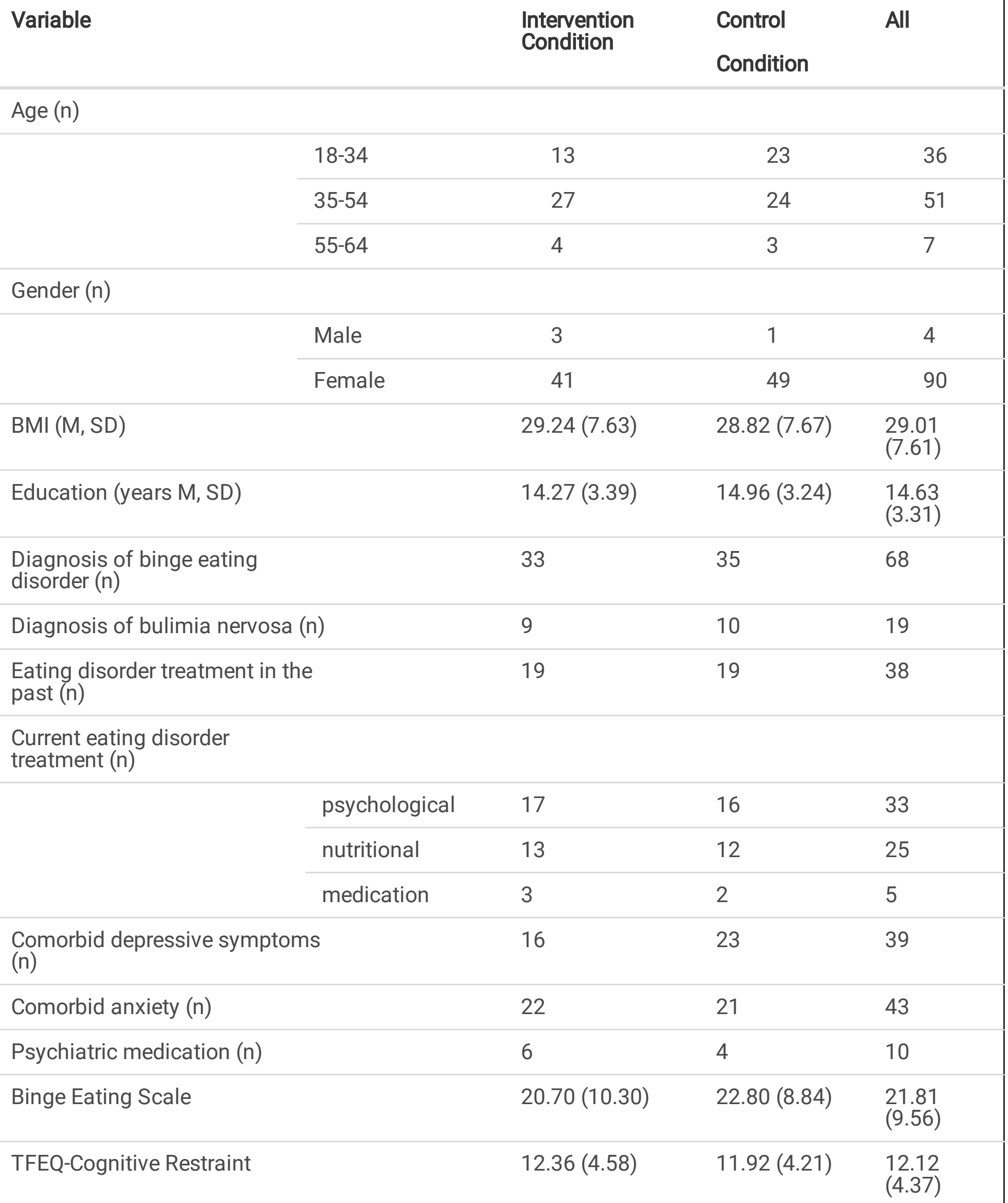




\begin{tabular}{|lccl|}
\hline Variable & $\begin{array}{l}\text { Intervention } \\
\text { Condition }\end{array}$ & $\begin{array}{l}\text { Control } \\
\text { Condition }\end{array}$ & All \\
\hline TFEQ-Disinhibition & $11.70(3.16)$ & $12.08(2.70)$ & $\begin{array}{l}11.90 \\
(2.91)\end{array}$ \\
\hline TFEQ-Hunger & $7.93(3.30)$ & $8.14(3.31)$ & 8.04 \\
\hline $\begin{array}{l}\text { Liking for high energy dense } \\
\text { foods }\end{array}$ & $5.44(1.53)$ & $5.29(1.42)$ & 5.36 \\
\hline $\begin{array}{l}\text { Wanting for high energy dense } \\
\text { foods }\end{array}$ & $4.37(2.08)$ & $4.51(1.69)$ & $\begin{array}{l}4.45 \\
(1.88)\end{array}$ \\
\hline $\begin{array}{l}\text { Food addiction possible } \\
\text { diagnosis (n) }\end{array}$ & 23 & 25 & 48 \\
\hline DASS-Anxiety & $5.54(5.99)$ & $6.96(6.30)$ & $\begin{array}{l}6.29 \\
(6.16)\end{array}$ \\
\hline DASS-Depression & $12.77(8.09)$ & $13.68(9.63)$ & 13.25 \\
\hline DASS-Stress & $17.50(8.95)$ & $18.68(8.49)$ & $\begin{array}{l}18.12 \\
(8.68)\end{array}$ \\
\hline
\end{tabular}

\section{Binge Eating Scale}

The full model including all fixed factors was different from the null model (GLMM: $X^{2}=40.12, d f=6, p<$ .0001). The Group by Time interaction was not significant ( $p=0.31)$, and therefore was removed from the model. The main effects of Group, Time, and Food Addiction were significant. Overall, those in the intervention condition reported lower scores (Mean $=18.24, S D=10.08)$ compared to those in the control condition (Mean=22.17, SD= 8.54). Those with a possible diagnosis of food addiction reported higher scores (Mean= 24.35, SD=9.48) compared to those with no diagnosis (Mean=16.39, SD=7.59). Post-hoc tests indicated that participants reported significantly lower scores at end of intervention (Mean $=19.68$, $\mathrm{SD}=8.47$ ) compared to baseline (Mean $=21.81, \mathrm{SD}=9.56$, Estimate $=-2.04, \mathrm{SE}=0.71, \mathrm{z}=-2.84 ; p=0.012$ ), and also at follow-up (Mean=19.32, SD=10.15) compared to baseline (Estimate $=-2.20, S E=0.72, z=$ $-3.06 ; p=0.006$ ). Scores at end of intervention and follow-up were not significantly different (Estimate= $0.16, \mathrm{SE}=0.74, \mathrm{z}=0.22 ; p=0.97)$.

\section{Three Factors Eating Questionnaire}

For the Cognitive Restraint subscale, the full model including all fixed factors was not significantly different from the null model (GLMM: $\mathrm{X}^{2}=1.24, \mathrm{df}=4, p=0.87$ ) and therefore no further analyses were conducted.

For the Hunger subscale, the full model including all fixed factors was significantly different from the null model (GLMM: $\left.X^{2}=12.33, \mathrm{df}=4, p=0.015\right)$. The interaction between Group and Time was significant; 
there was a trend for participants in the intervention condition to score lower at the end of the intervention (Mean=6.97, $\mathrm{SD}=3.61$ ) compared to baseline (Mean=7.93, $\mathrm{SD}=3.30$; Estimate= 0.92, $\mathrm{SE}=0.37, \mathrm{df}=84.8, \mathrm{t}$ ratio $=2.43, p=0.07$ ) whereas those in the control condition did not score significantly differently over time (Mean baseline $=8.14, \mathrm{SD}=31$, Mean post $=8.39$, Estimate $=-0.19, \mathrm{SE}=0.34, \mathrm{df}=83.3, \mathrm{t}$ ratio $=-0.55$, $p=0.94$; Figure 3 ). Overall, those with a possible diagnosis of food addiction reported higher scores (Mean=8.54, SD=3.24) compared to those without a diagnosis (Mean=7.27, SD=3.40).

For the Disinhibition subscale, the full model including all fixed factors was significantly different from the null model (GLMM: $\left.X^{2}=21.30, \mathrm{df}=4, p<0.0001\right)$. The interaction between Group and Time was not significant $(p=0.12)$, and therefore was removed from the model. The main effect of Group was not significant either. The main effect of Time was significant; participants reported significantly lower scores at end of intervention (Mean=11.15, SD=3.27) compared to baseline (Mean=11.90, SD=2.91). Those with a possible diagnosis of food addiction reported higher scores (Mean=12.31, SD $=2.80$ ) compared to those without a diagnosis (Mean=10.80, SD=3.20).

\section{High-energy dense food liking and wanting}

The full model for "food liking" was significantly different from the null model (GLMM: $X^{2}=45.17, \mathrm{df}=6$, $p<.0001)$. The interaction between Group and Time was significant. Participants in the intervention condition scored lower at the end of intervention (Mean $=4.58, S D=1.54$, Estimate $=0.70, S E=0.18, d f=$ 162 , $\mathrm{t}$ ratio $=3.78, p=0.002$ ), and follow-up (Mean= 4.04, $\mathrm{SD}=1.67$; Estimate $=1.23, \mathrm{SE}=0.18, \mathrm{df}=162 \mathrm{t}$ ratio $=6.51, p<0.0001)$ compared to baseline (Mean=5.44, SD=1.53), whereas those in the control condition did not score significantly differently over time (Mean baseline= 5.29, $S D=1.42$, Mean end of intervention= 5.15, $S D=1.52$; Mean follow-up=4.97, $S D=1.67$; baseline vs. end of intervention: Estimate= $0.11, \mathrm{SE}=0.16, \mathrm{df}=160, \mathrm{t}$ ratio $=-0.67, p=0.98$; end of intervention vs. follow-up: Estimate= 0.30, $\mathrm{SE}=0.17$, $\mathrm{df}=161$, t ratio $=1.77, p=0.48$; Figure 4 ). The main effect of Food Addiction was not significant.

For the variable "food wanting", the full model including all fixed factors was significantly different from the null model (GLMM: $\left.\mathrm{X}^{2}=21.25, \mathrm{df}=6, p<0.0016\right)$. The interaction between Group and Time was not significant ( $p=0.49$ ), and therefore was removed from the model. The main effect of Time was significant; participants reported significantly lower scores at end of intervention (Mean=3.75, $S D=1.91$; Estimate $=0.64, \mathrm{SE}=0.18, \mathrm{z}=-3.51, p=0.0013$ ) and follow-up (Mean= 3.71, $\mathrm{SD}=1.95$; Estimate $=-0.66, \mathrm{SE}=$ $0.18, z=-3.57, p=0.001)$, compared to baseline (Mean=4.45, SD=1.87). The difference between the end of intervention and follow-up scores was not significant (Estimate $=0.02, \mathrm{SE}=0.19, \mathrm{z}=-0.11, p=0.99$ ). The main effects of Group and Food Addiction were not significant.

\section{Depression, Anxiety and Stress}

The full model for the variable Depression was significantly different from the null model (GLMM: $X^{2}=$ $28.46, \mathrm{df}=5, p<.0001)$. The interaction between Group and Time was significant $(p=0.046)$. Participants in the intervention condition scored significantly lower at end of intervention compared to baseline (Mean baseline $=12.77, \mathrm{SD}=9.09$, Mean end of intervention $=8.64, \mathrm{SD}=7.43$; Estimate $=3.73, \mathrm{SE}=1.25, \mathrm{df}=163, \mathrm{t}$ 
ratio $=2.49, p=0.037$ ) and lower at follow-up compared to baseline (Mean follow-up= 6.90, SD=6.12, Estimate $=5.50, \mathrm{SE}=1.26 \mathrm{df}=163, \mathrm{t}$ ratio $=4.36, p=0.0003)$. Participants did not score significantly different at end of intervention compared to follow-up (estimate $=-1.76, \mathrm{SE}=1.30, \mathrm{df}=154, \mathrm{t}$ ratio $=-1.35$, $p=0.75$ ). In the control condition, there were not significant differences between baseline (Mean $=13.68$, $S D=9.63$ ) and end of intervention scores (Mean = 10.23, $S D=8.82$, Estimate = 3.08, $S E=1.13, d f=159, t$ ratio $=2.73, p=0.07$ ); between baseline and follow-up scores (Mean follow-up= $12.73, \mathrm{SD}=7.44$, Estimate $=1.48, \mathrm{SE}=1.17 \mathrm{df}=160, \mathrm{t}$ ratio $=1.26, p=0.80$ ); or between end of intervention and follow-up (Estimate $=1.60, \mathrm{SE}=1.20, \mathrm{df}=156, \mathrm{t}$ ratio $=1.33, p=0.76$; Figure 5 ).

For the Stress subscale, the full model including all fixed factors was significantly different from the null model (GLMM: $\left.X^{2}=30.66, \mathrm{df}=5, p<0.0001\right)$. The interaction between Group and Time was not significant $(p=0.16)$, and therefore was removed from the model. The main effect of Group was not significant either. The main effect of Time was significant. Participants reported overall higher scores at baseline (Mean=18.12, SD=8.68) compared to end of intervention (Mean=14.23, SD=8.32, Estimate= $-3.70, S E=0.84, z=-4.39, p<0.0001$ ) and higher scores at baseline compared to follow-up (Mean followup $=14.27, S D=8.61$, Estimate $=-3.72, S E=0.85, z=-4.35, p<0.0001)$. There were not significant differences between scores at end of intervention and follow-up (Estimate $=0.02, \mathrm{SE}=0.88, \mathrm{z}=0.02, p=$ 1.0).

For the Anxiety subscale, the square root transformation was applied to match the normality assumptions. The full model including all fixed factors was significantly different from the null model (GLMM: $\mathrm{X}^{2}=20.02, \mathrm{df}=5, p<0.0012$ ). The interaction between Group and Time was not significant ( $p=$ $0.34)$, and therefore was removed from the model. The main effect of Group was not significant either. The main effect of Time was significant. Participants reported overall higher scores at baseline (Mean= $5.0, S D=6.16$ ) compared to end of intervention (Mean= 4.07, $S D=5.50$, Estimate= $-0.37, S E=0.09, z=$ -3.76, $p<0.0001$ ) and higher scores at baseline compared to follow-up (Mean follow-up= 4.37, SD= 5.64, Estimate $=-0.27, \mathrm{SE}=0.10, z=-2.69, p<0.019)$. No significant differences between end of intervention and follow-up scores were found (Estimate $=-0.009, \mathrm{SE}=0.10, \mathrm{z}=-0.91, p=0.63$ ).

Table 2 describes the parameters of the generalised linear mixed models calculated to assess betweengroup differences on eating behaviour, eating-related attitudes and depression, anxiety and stress over time. 
Table 2

Parameters of the generalised liner mixed models calculated to assess between-group differences on eating behaviour, eating-related attitudes and depression, anxiety and stress over time. TFEQ = Three

Factors Eating Questionnaire. DASS= Depression Anxiety and Stress Scales.

\begin{tabular}{|c|c|c|c|c|c|}
\hline & & Estimate & SE & $t$ & $p$ \\
\hline \multicolumn{6}{|c|}{ Binge Eating Scale } \\
\hline & Intercept & 19.14 & 1.39 & 13.74 & \\
\hline & Group & -3.18 & 1.58 & -2.01 & 0.046 \\
\hline & $\begin{array}{l}\text { Time (baseline vs. end of } \\
\text { intervention) }\end{array}$ & -2.04 & 0.71 & -2.84 & 0.003 \\
\hline & Time (baseline vs. follow-up) & -2.20 & 0.72 & -3.06 & \\
\hline & Food addiction & 8.16 & 1.57 & 5.16 & $<0.0001$ \\
\hline \multicolumn{6}{|l|}{ TFEQ - Hunger } \\
\hline & Intercept & 7.44 & 0.55 & 13.37 & \\
\hline & Group & -0.23 & 0.66 & -0.33 & \\
\hline & Time & 0.18 & 0.33 & 0.56 & \\
\hline & Food addiction & 1.39 & 0.63 & 2.20 & 0.028 \\
\hline & Group x Time & -1.11 & 0.50 & -2.21 & 0.028 \\
\hline \multicolumn{6}{|c|}{ TFEQ -Disinhibition } \\
\hline & Intercept & 11.37 & 0.49 & 22.75 & \\
\hline & Group & -0.67 & 0.57 & -1.16 & 0.24 \\
\hline & Time & -0.66 & 0.20 & -3.23 & 0.0016 \\
\hline & Food addiction & 1.66 & 0.57 & 2.87 & 0.005 \\
\hline \multicolumn{6}{|c|}{$\begin{array}{l}\text { Liking for high energy dense } \\
\text { foods }\end{array}$} \\
\hline & Intercept & 5.11 & 0.25 & 19.67 & \\
\hline & Group & 0.14 & 0.31 & 0.44 & \\
\hline & $\begin{array}{l}\text { Time (baseline vs. end of } \\
\text { intervention) }\end{array}$ & -0.11 & 0.16 & -0.68 & \\
\hline & Time (baseline vs. follow-up) & -0.30 & 0.16 & -1.80 & \\
\hline & Food addiction & 0.36 & 0.29 & 1.25 & 0.21 \\
\hline & Group x Time (end of intervention) & -0.59 & 0.24 & -2.40 & 0.001 \\
\hline
\end{tabular}




\begin{tabular}{|c|c|c|c|c|c|}
\hline & & Estimate & SE & 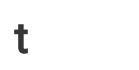 & $p$ \\
\hline & Group x Time (follow-up) & -0.93 & 0.25 & -3.70 & \\
\hline \multicolumn{6}{|c|}{ Wanting for high energy dense foods } \\
\hline & Intercept & 4.35 & 0.30 & 14.32 & \\
\hline & Group & -0.37 & 0.34 & -1.09 & 0.27 \\
\hline & $\begin{array}{l}\text { Time (baseline vs. end of } \\
\text { intervention) }\end{array}$ & -0.64 & 0.18 & -3.51 & 0.0002 \\
\hline & Time (baseline vs. follow-up) & -0.66 & 0.18 & -3.57 & \\
\hline & Food addiction & 0.53 & 0.33 & 1.56 & 0.12 \\
\hline \multicolumn{6}{|c|}{ DASS-21 Depression } \\
\hline & Intercept & 13.68 & 1.14 & 11.92 & \\
\hline & Group & -0.90 & 1.67 & -0.54 & \\
\hline & $\begin{array}{l}\text { Time (baseline vs. end of } \\
\text { intervention) }\end{array}$ & -3.08 & 1.11 & -2.77 & \\
\hline & Time (baseline vs. follow-up) & -1.48 & 1.15 & -1.28 & \\
\hline & $\begin{array}{l}\text { Group X Time (baseline vs. end of } \\
\text { int.) }\end{array}$ & -0.65 & 1.66 & -0.39 & 0.046 \\
\hline & Group x Time (baseline vs. follow-up & -4.01 & 1.69 & -2.36 & \\
\hline \multicolumn{6}{|l|}{ DASS-21 Stress } \\
\hline & Intercept & 19.37 & 1.12 & 17.22 & \\
\hline & Group & -2.66 & 1.52 & -1.74 & 0.08 \\
\hline & $\begin{array}{l}\text { Time (baseline vs. end of } \\
\text { intervention) }\end{array}$ & -3.70 & 0.84 & -4.39 & $<0.0001$ \\
\hline & Time (baseline vs. follow-up) & -3.72 & 0.85 & -4.35 & \\
\hline \multicolumn{6}{|l|}{ DASS-21 Anxiety } \\
\hline & Intercept & 2.64 & 0.14 & 18.19 & \\
\hline & Group & -0.37 & 0.20 & -1.85 & 0.07 \\
\hline & $\begin{array}{l}\text { Time (baseline vs. end of } \\
\text { intervention) }\end{array}$ & -0.37 & 0.09 & -3.76 & 0.0005 \\
\hline & Time (baseline vs. follow-up) & -0.27 & 0.10 & -2.69 & \\
\hline
\end{tabular}


The aim of this study was to expand findings on the impact of FoodT, a food-specific inhibitory training delivered through a mobile application, on eating behaviour, eating-related attitudes and psychological wellbeing in a community sample of people with disinhibited eating in Italy, during COVID-19. The use of FoodT was tested against a waiting list over two weeks, with an additional measurement taken one week later (follow-up). Comparing retention rates and number of sessions completed to those reported in a recent study testing the same form (App-based) and content of the training (food-specific) [26], retention rates at the end of the intervention were slightly lower (i.e., $77 \%$ vs $80 \%$ ) in the intervention group, and overall lower than those in the control condition (86\%). The average number of sessions completed was 11 , and just over half of the participants completed at least 10 sessions over two weeks, as had been recommended by the study team. When the number of sessions was lowered to eight in total (based on the feasibility threshold used in Keeler et al. [26]), then the number of participants meeting the criterion reached $68 \%$. This is lower than the $80 \%$ found in Keeler et al.[26] Despite this, retention rates and number of sessions completed appear particularly remarkable considering that this study, unlike the previous ones, was conducted at a time characterised by high levels of uncertainty, distress, and disruptions to life routines. Also, although the sample was recruited from the community, over $70 \%$ reported a clinical diagnosis of binge eating disorder and $20.4 \%$ reported a diagnosis of bulimia nervosa. Half of the sample had a possible diagnosis of food addiction and overall participants had moderate levels of binge eating. In terms of psychological wellbeing, at the time of testing participants were suffering from extremely high levels of stress, severe depressive symptoms, and moderate levels of anxiety. The characteristics of the sample mean that the conclusions which arise from this study might be relevant for clinical populations too (i.e., participants recruited from clinical services).

The intervention condition was associated with significantly lower levels of perceived hunger, high-energy dense food liking and depression symptoms, whereas it was not associated with significantly lower levels of binge eating symptoms. Some of these findings replicate previous ones i.e., reduction in high-dense energy foods valuation and no changes in binge eating, from a study conducted in patients receiving treatment for binge eating symptoms [26]. The finding related to a decrease in perceived hunger (a construct including both internally regulated and externally triggered hunger) is important, as previous experimental studies have proved the association between hunger, impaired response inhibition and an attentional bias towards foods [43]. Also, hunger has been associated with more intense cravings and a preference for food over non-food stimuli compared to satiation [44]. Thus, the reduction in perceived hunger is potentially important as it might have an effect on response inhibition, attentional bias to food and cravings, which are all associated to over consumption of highly palatable foods.

A similar argument could be made for the reduced liking of high-energy dense foods, as this process has been associated with a tendency to prefer these foods in a forced-choice task [45]. Interestingly though, this preferred choice did not translate into greater consumption of high palatable foods during a bogus taste test [45]. Consumption of food was not measured in this study, and therefore it is not possible to conclude whether reduced hunger and/or liking of high-energy dense foods would translate to real-world eating behaviour. Whilst inhibitory control trainings have been associated with less consumption of food or alcohol compared to control conditions, in laboratory studies [46], real world effects are more mixed. 
For example, reduced food liking has been shown alongside weight loss or reduced intake in some studies $[47,48]$ but not others $[49,50]$.

Taken these findings together, one could suggest that food specific inhibitory control trainings might impact on some key mechanisms of disinhibited hunger (e.g., perceived hunger and liking of high-energy dense foods) but that it may need to be combined with other forms of trainings (e.g., approach/avoidance trainings) in order to exert an impact on binge-eating. For example, a recent study comparing nicotine-avoidance training with nicotine-inhibition training in smokers found that avoidance training was more effective in reducing daily smoking in the short term [51].

In this study, those receiving inhibitory control training reported lower levels of depression symptoms over time. The assessment of mood is often neglected in the evaluation of motor response training procedures, and yet negative mood is strongly associated with unhealthy food consumption $[27,52,53]$. Future studies might seek to replicate this finding, and examine the mechanisms through which foodspecific inhibitory control might exert a beneficial impact on mood. This study was conducted during COVID-19, and it is possible that engaging into a health-related activity might have given a sense of purpose to participants, boosting their mood. On the other hand, it is possible that there is something specific about inhibitory control training, which leads to improved mood, such as an increased sense of control or confidence over one's behavioural choices.

\section{Strengths and limitations}

The main strengths of this study are the use of an App-based training which was used before within the same patient group, thus enabling replication and broadening of findings, the use of a randomised controlled design, and the assessment of multiple outcomes, above and beyond binge eating symptoms. Limitations include the lack of a formal assessment of eating disorders and the lack of an objective measure of food consumption, higher than desirable attrition rates in the intervention condition, and the very low number of participants of non-female gender. Despite these limitations, the study was conducted at a time of severe restrictions and many difficulties accessing clinical services in Italy. Findings appear encouraging and in line with previous evidence, which demonstrates the feasibility and benefits of using food-specific inhibitory control training.

\section{What is already known on this subject?}

Food-specific inhibitory control training is associated with positive changes in health behaviour. Findings in people with disinhibited eating and a possible diagnosis of eating disorders are mixed.

\section{What this study adds?}

This study tested the use of an App-based food-specific inhibitory control training in a community sample with disinhibited eating, during the COVID-19 Pandemic. Findings corroborated the feasibility of the training and expanded knowledge on its impact. In particular, this study highlighted the impact of training 
on perceived hunger and depression, opening interesting questions on the mechanisms which might explain these effects.

\section{Declarations}

\section{Funding}

This paper presents independent research funded by the NIHR under its Research for Patient Benefit (RfPB) Programme (PB-PG-1216-20044). The views expressed are those of the author(s) and not necessarily those of the NIHR or the Department of Health and Social Care. Valentina Cardi is supported by a grant from MIUR (Dipartimenti di Eccellenza DM 11/05/2017 n. 262) to the Department of General Psychology. Valentina Meregalli was supported by the "Department of excellence 2018-2022" initiative of the Italian Ministry of education (MIUR) awarded to the Department of Neuroscience - University of Padova.

\section{Competing Interests}

The authors have no relevant financial or non-financial interests to disclose.

\section{Author Contributions}

All authors contributed to the study conception and design. Material preparation, data collection and analysis were performed by Valentina Cardi, Valentina Meregalli, Elisa Di Rosa, Rossella Derrigo and Chiara Faustini. The first draft of the manuscript was written by Valentina Cardi and all authors commented on previous versions of the manuscript. All authors read and approved the final manuscript.

\section{Data Availability}

Data are available on request to the corresponding author.

\section{Ethics approval}

This study was performed in line with the principles of the Declaration of Helsinki. Approval was granted by the Ethics Committee for psychological research, at the University of Padova (protocol number: 3527).

\section{Consent to participate}

Informed consent was obtained from all participants included in the study.

Consent to publish

All participants consented to the publication of non-identifiable information.

\section{References}


1. van Hoeken D, Hoek HW (2020) Review of the burden of eating disorders: mortality, disability, costs, quality of life, and family burden. Curr Opin Psychiatry 33:521-527. https://doi.org/10.1097/YC0.0000000000000641

2. Södersten P, Brodin U, Sjöberg J, Zandian M, Bergh C (2019) Treatment outcomes for eating disorders in Sweden: data from the national quality registry. BMJ open 9. https://doi.org/10.1136/BMJOPEN-2018-024179

3. Frostad S, Danielsen YS, Rekkedal GA, Jevne C, Dalle Grave R, Rø Ø, Kessler U (2018) Implementation of enhanced cognitive behaviour therapy (CBT-E) for adults with anorexia nervosa in an outpatient eating-disorder unit at a public hospital. J Eat disorders 6. https://doi.org/10.1186/S40337-0180198-Y

4. Jenkins PE, Morgan C, Houlihan C (2019) Outpatient CBT for Underweight Patients with Eating Disorders: Effectiveness Within a National Health Service (NHS) Eating Disorders Service. Behav Cogn Psychother 47:217-229. https://doi.org/10.1017/S1352465818000449

5. Dobrescu SR, DInkler L, Gillberg C, Råstam M, Gillberg C, Wentz E (2020) Anorexia nervosa: 30-year outcome. Br J psychiatry: J mental Sci 216:97-104. https://doi.org/10.1192/BJP.2019.113

6. Eddy KT, Tabri N, Thomas JJ, Murray HB, Keshaviah A, Hastings E, Edkins K, Krishna M, Herzog DB, Keel PK, Franko DL (2017) Recovery From Anorexia Nervosa and Bulimia Nervosa at 22-Year FollowUp. J Clin Psychiatry 78:184-189. https://doi.org/10.4088/JCP.15M10393

7. Taquet M, Geddes JR, Luciano S, Harrison PJ (2021) Incidence and outcomes of eating disorders during the COVID-19 pandemic. Br J psychiatry: J mental Sci. https://doi.org/10.1192/BJP.2021.105

8. di Renzo L, Gualtieri P, Pivari F, Soldati L, Attinà A, Cinelli G, Cinelli G, Leggeri C, Caparello G, Barrea L, Scerbo F, Esposito E, de Lorenzo A (2020) Eating habits and lifestyle changes during COVID-19 lockdown: an Italian survey. J translational Med 18. https://doi.org/10.1186/S12967-020-02399-5

9. Cecchetto C, Aiello M, Gentili C, lonta S, Osimo SA (2021) Increased emotional eating during COVID19 associated with lockdown, psychological and social distress. Appetite 160. https://doi.org/10.1016/J.APPET.2021.105122

10. Cardi V, Albano G, Gentili C, Sudulich L (2021) The impact of emotion regulation and mental health difficulties on health behaviours during COVID19. J Psychiatr Res 143:409-415. https://doi.org/10.1016/J.JPSYCHIRES.2021.10.001

11. Nightingale BA, Cassin SE (2019) Disordered Eating Among Individuals with Excess Weight: a Review of Recent Research. Curr Obes Rep 8:112-127. https://doi.org/10.1007/S13679-019-00333-5

12. American Psychiatric Association (2013) Diagnostic and Statistical Manual of Mental Disorders. American Psychiatric Association

13. Byrne ME, Shank LM, Altman DR, Swanson TN, Ramirez E, Moore NA, Rubin SG, LeMay-Russell S, Parker MN, Kaufman RE, Yang SB, Torres SL, Brady SM, Kelly NR, Tanofsky-Kraff M, Yanovski JA (2021) Inhibitory control and negative affect in relation to food intake among youth. Appetite 156. https://doi.org/10.1016/J.APPET.2020.104858 
14. van Malderen E, Kemps E, Verbeken S, Goossens L (2021) Food for mood: Experimentally induced negative affect triggers loss of control over eating in adolescents with low inhibitory control. Int $\mathrm{J}$ Eat Disord 54:388-398. https://doi.org/10.1002/EAT.23422

15. Dohle S, Diel K, Hofmann W (2018) Executive functions and the self-regulation of eating behavior: A review. Appetite 124:4-9. https://doi.org/10.1016/J.APPET.2017.05.041

16. Lavagnino L, Arnone D, Cao B, Soares JC, Selvaraj S (2016) Inhibitory control in obesity and binge eating disorder: A systematic review and meta-analysis of neurocognitive and neuroimaging studies. Neurosci Biobehav Rev 68:714-726. https://doi.org/10.1016/J.NEUBIOREV.2016.06.041

17. Rosenbaum DL, White KS (2015) The relation of anxiety, depression, and stress to binge eating behavior. J Health Psychol 20:887-898. https://doi.org/10.1177/1359105315580212

18. Loeber S, Rustemeier M, Paslakis G, Pietrowsky R, Müller A, Herpertz S (2018) Mood and restrained eating moderate food-associated response inhibition in obese individuals with binge eating disorder. Psychiatry Res 264:346-353. https://doi.org/10.1016/J.PSYCHRES.2018.03.081

19. Rebetez MML, Rochat L, Billieux J, Gay P, van der Linden M (2015) Do emotional stimuli interfere with two distinct components of inhibition? Cognition \& emotion 29:559-567. https://doi.org/10.1080/02699931.2014.922054

20. Schulte EM, Gearhardt AN (2021) Attributes of the food addiction phenotype within overweight and obesity. Eat weight disorders: EWD 26:2043-2049. https://doi.org/10.1007/S40519-020-01055-7

21. Gearhardt AN, Corbin WR, Brownell KD (2009) Preliminary validation of the Yale Food Addiction Scale. Appetite 52:430-436. https://doi.org/10.1016/J.APPET.2008.12.003

22. Meule A, Kübler A (2012) Food cravings in food addiction: the distinct role of positive reinforcement. Eat Behav 13:252-255. https://doi.org/10.1016/J.EATBEH.2012.02.001

23. Joyner MA, Gearhardt AN, White MA (2015) Food craving as a mediator between addictive-like eating and problematic eating outcomes. Eat Behav 19:98-101. https://doi.org/10.1016/J.EATBEH.2015.07.005

24. Allom V, Mullan B, Hagger M (2016) Does inhibitory control training improve health behaviour? A meta-analysis. Health Psychol Rev 10:168-186. https://doi.org/10.1080/17437199.2015.1051078

25. Aulbach MB, Knittle K, Haukkala A (2019) Implicit process interventions in eating behaviour: a metaanalysis examining mediators and moderators. Health Psychol Rev 13:179-208. https://doi.org/10.1080/17437199.2019.1571933

26. Keeler JL, Chami R, Cardi V, Hodsoll J, Bonin E, MacDonald P, Treasure J, Lawrence N (2022) Appbased food-specific inhibitory control training as an adjunct to treatment as usual in binge-type eating disorders: A feasibility trial. Appetite 168. https://doi.org/10.1016/J.APPET.2021.105788

27. Chami R, Cardi V, Lawrence N, Macdonald P, Rowlands K, Hodsoll J, Treasure J (2020) Targeting binge eating in bulimia nervosa and binge eating disorder using inhibitory control training and implementation intentions: a feasibility trial. Psychol Med. https://doi.org/10.1017/S0033291720002494 
28. Polivy J, Herman CP (2020) Overeating in Restrained and Unrestrained Eaters. Frontiers in nutrition 7:. https://doi.org/10.3389/FNUT.2020.00030

29. Lancaster GA, Dodd S, Williamson PR (2004) Design and analysis of pilot studies: recommendations for good practice. J Eval Clin Pract 10:307-312. https://doi.org/10.1111/J..2002.384.DOC.X

30. Sim J, Lewis M (2012) The size of a pilot study for a clinical trial should be calculated in relation to considerations of precision and efficiency. J Clin Epidemiol 65:301-308.

https://doi.org/10.1016/J.JCLINEPI.2011.07.011

31. Lawrence NS, van Beurden S, Javaid M, Mostazir MM (2018) Mass dissemination of web and smartphone-delivered food response inhibition training to reduce unhealthy snacking. Appetite 130:309. https://doi.org/10.1016/J.APPET.2018.05.207

32. Gormally J, Black S, Daston S, Rardin D (1982) The assessment of binge eating severity among obese persons. Addict Behav 7:47-55. https://doi.org/10.1016/0306-4603(82)90024-7

33. Stunkard AJ, Messick S (1985) The three-factor eating questionnaire to measure dietary restraint, disinhibition and hunger. J Psychosom Res 29:71-83. https://doi.org/10.1016/00223999(85)90010-8

34. Henry JD, Crawford JR (2005) The short-form version of the Depression Anxiety Stress Scales (DASS-21): construct validity and normative data in a large non-clinical sample. $\mathrm{Br} \mathrm{J}$ Clin Psychol 44:227-239. https://doi.org/10.1348/014466505X29657

35. Blechert J, Meule A, Busch NA, Ohla K (2014) Food-pics: an image database for experimental research on eating and appetite. Front Psychol 5. https://doi.org/10.3389/FPSYG.2014.00617

36. Bates D, Mächler M, Bolker B, Walker S (2015) Fitting Linear Mixed-Effects Models Using Ime4. J Stat Softw. https://doi.org/10.18637/jss.v067.i01. 67:

37. Hartig F (2022) DHARMa: Residual Diagnostics for Hierarchical (Multi-Level / Mixed) Regression Models. R package version 0.4.5. http://florianhartig.github.io/DHARMa/

38. Barr DJ, Levy R, Scheepers C, Tily HJ (2013) Random effects structure for confirmatory hypothesis testing: Keep it maximal. J Mem Lang 68:255-278. https://doi.org/10.1016/J.JML.2012.11.001

39. Hothorn T, Bretz F, Westfall $P$ (2008) Simultaneous inference in general parametric models. Biometrical J Biometrische Z 50:346-363. https://doi.org/10.1002/BIMJ.200810425

40. Marcus MD, Wing RR, Hopkins J (1988) Obese binge eaters: affect, cognitions, and response to behavioural weight control. J Consult Clin Psychol 56:433-439. https://doi.org/10.1037//0022006X.56.3.433

41. Marchesini G, Cuzzolaro M, Mannucci E, Dalle Grave R, Gennaro M, Tomasi F, Barantani EG, Melchionda N (2004) Weight cycling in treatment-seeking obese persons: data from the QUOVADIS study. Int J Obes Relat metabolic disorders: J Int Association Study Obes 28:1456-1462. https://doi.org/10.1038/SJ.IJ0.0802741

42. Lovibond SH, Lovibond PF (1996) Manual for the depression anxiety stress scales, 2nd edn. Psychology Foundation of Australia 
43. Loeber S, Grosshans M, Korucuoglu O, Vollmert C, Vollstädt-Klein S, Schneider S, Wiers RW, Mann K, Kiefer F (2012) Impairment of inhibitory control in response to food-associated cues and attentional bias of obese participants and normal-weight controls. International journal of obesity (2005) 36:1334-1339. https://doi.org/10.1038/IJO.2011.184

44. Reents J, Seidel AK, Wiesner CD, Pedersen A (2020) The Effect of Hunger and Satiety on MoodRelated Food Craving. Frontiers in psychology 11:. https://doi.org/10.3389/FPSYG.2020.568908

45. Eichin KN, Georgii C, Arend A-K, van Dyck Z, Blechert J (2022) (Mouse cursor)-Tracking food decisions in binge eating disorder reveals preference for high-energy foods and a role of BMI. Appetite 170:105890. https:// doi.org/10.1016/J.APPET.2021.105890

46. Jones A, di Lemma LCG, Robinson E, Christiansen P, Nolan S, Tudur-Smith C, Field M (2016) Inhibitory control training for appetitive behaviour change: A meta-analytic investigation of mechanisms of action and moderators of effectiveness. Appetite 97:16-28. https://doi.org/10.1016/J.APPET.2015.11.013

47. Lawrence NS, Verbruggen F, Morrison S, Adams RC, Chambers CD (2015) Stopping to food can reduce intake. Effects of stimulus-specificity and individual differences in dietary restraint. Appetite 85:91-103. https://doi.org/10.1016/J.APPET.2014.11.006

48. Camp B, Lawrence NS (2019) Giving pork the chop: Response inhibition training to reduce meat intake. Appetite 141:104315. https://doi.org/10.1016/j.appet.2019.06.007

49. Adams RC, Button KS, Hickey L, Morrison S, Smith A, Bolus W, Coombs E, Randolph S, Hunt R, Kim D, Chambers CD, Lawrence NS (2021) Food-related inhibitory control training reduces food liking but not snacking frequency or weight in a large healthy adult sample. Appetite 167:105601. https://doi.org/10.1016/j.appet.2021.105601

50. Najberg H, Rigamonti M, Mouthon M, Spierer L (2021) Modifying food items valuation and weight with gamified executive control training. Royal Soc Open Sci 8:191288. https://doi.org/10.1098/rsos.191288

51. Machulska A, Rinck M, Klucken T, Kleinke K, Wunder J-C, Remeniuk O, Margraf J (2022) "Push it!" or "Hold it!"? A comparison of nicotine-avoidance training and nicotine-inhibition training in smokers motivated to quit. Psychopharmacology 239:105-121. https://doi.org/10.1007/S00213-021-060585

52. Cardi V, Leppanen J, Treasure J (2015) The effects of negative and positive mood induction on eating behaviour: A meta-analysis of laboratory studies in the healthy population and eating and weight disorders. Neurosci Biobehav Rev 57:299-309. https://doi.org/10.1016/J.NEUBIOREV.2015.08.011

53. Haedt-Matt AA, Keel PK (2011) Revisiting the affect regulation model of binge eating: a metaanalysis of studies using ecological momentary assessment. Psychol Bull 137:660-681. https://doi.org/10.1037/A0023660

\section{STATEMENTS AND DECLARATIONS}


Figures

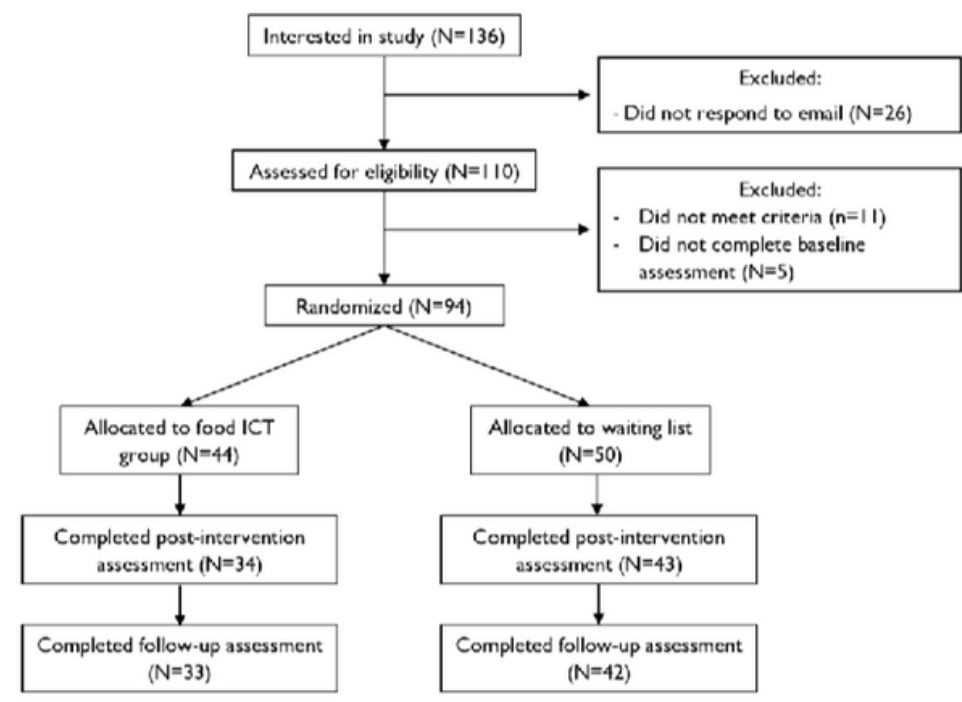

\section{Figure 1}

Consort diagram describing the flow of participation in the study 


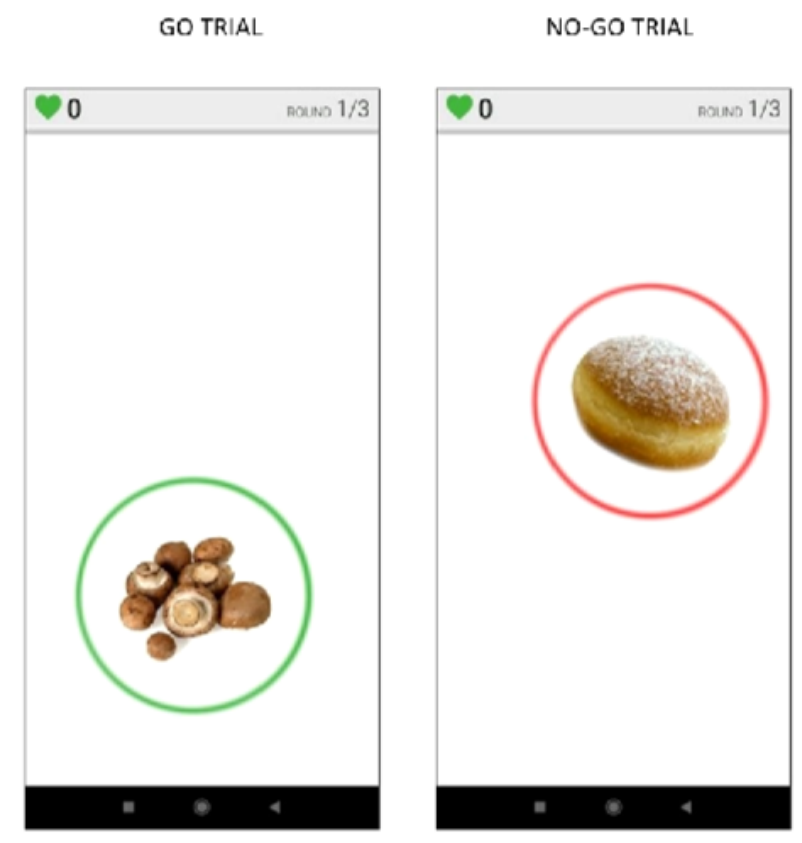

Figure 2

Examples of "go" (low energy dense food, green circled) and "no go" stimuli (high energy dense food, red circled) presented by the FoodT app, during the training.

\section{Figure 3}

Differences between the intervention and control conditions, over time, in levels of hunger. The horizontal lines within the boxplot indicate the median. The boxes extend from the lower to the upper quartile and the whiskers indicate the interquartile range above the upper quartile (max) or below the lower quartile (min)

\section{Figure 4}

Differences between the intervention and control conditions, over time, in levels of liking for high energy dense foods. The horizontal lines within the boxplot indicate the median. The boxes extend from the 
lower to the upper quartile and the whiskers indicate the interquartile range above the upper quartile (max) or below the lower quartile (min).

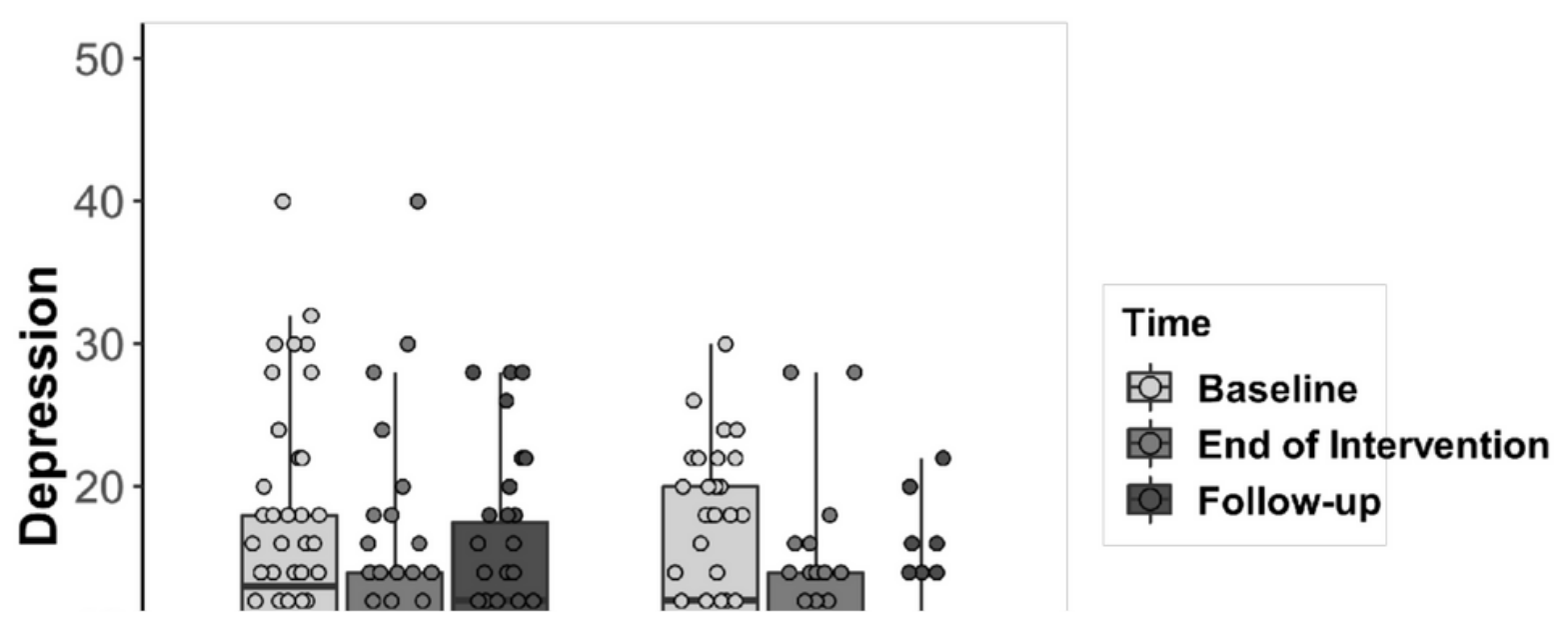

\section{Figure 5}

Differences between the intervention and control conditions, over time, in levels of Depression. The horizontal lines within the boxplot indicate the median. The boxes extend from the lower to the upper quartile and the whiskers indicate the interquartile range above the upper quartile (max) or below the lower quartile (min). 